\title{
Supporting First-Year Students During the Transition to Higher Education: The Importance of Quality and Source of Received Support for Student Well-Being
}

\author{
Rebecca Maymon \\ McGill University, Montreal, Canada \\ Nathan C. Hall \\ McGill University, Montreal, Canada \\ Jason M. Harley \\ McGill University, Montreal, Canada; Research Institute of the McGill University Health Centre, Montreal, Canada; \\ University of Alberta, Edmonton, Canada
}

\begin{abstract}
The present exploratory study evaluated perceptions of actual support received in relation to stress and well-being among first-year students attending Canadian and U.S. higher education institutions $(\mathrm{N}=126)$. Given that traditional assessments of received support account only for how often support was received, the present research examined unique effects of support quality in addition to frequency with respect to four distinct sources of support (family, friends, faculty/staff, institution). Following from empirical confirmation of received support frequency (RSF) and received support quality (RSQ) as distinguishable constructs, RSQ was found to significantly mediate effects of RSF across varied well-being outcomes (e.g., stress, burnout, quitting intentions) in relation to family, faculty/staff, and institution support. Overall, study findings highlight the importance of evaluating the quality of support received by first-year students during the transition to higher education and show faculty/staff support to be an important contributor to student well-being.
\end{abstract}

Keywords: Well-being; first year experience; transition; student support.

\section{Introduction}

Social-emotional well-being has been consistently identified in empirical research as a critical component of first-year student success (for a systematic review, see van der Zanden, Denessen, Cillessen, \& Meijer, 2018), with students who receive social support being more likely to optimally adjust to the transition to higher education. Research conducted in multiple countries has identified students' transition experiences to be a potential source of stress during their first year of post-secondary studies (e.g., Australia: Molloy, 2016; Canada: MacDonald, 2017; United Kingdom: Coughlan, 2015), with trends over recent years showing increasing stressors for those entering higher education (e.g., competitively, financially, etc.). Despite growing research on stress in higher education, stress and negative consequences related to coping and psychological well-being remain

This work is licensed under a Creative Commons Attribution 4.0 International Licence. As an open access journal, articles are free to use with proper attribution. ISSN: 2205-0795 
a pervasive issue (Welle \& Graf, 2011), with qualitative assessments of first-year experiences showing stress to be one of the primary factors influencing students' transition to university (Wrench, Garrett, \& King, 2013).

In attempts to identify critical resources that may help to mitigate negative consequences of stress for first-year students, research has shown social support to promote more adaptive coping and healthier behaviours (McKinley, 2013) and reduce stress during the transition to university life (Miczo, Miczo, \& Johnson, 2006; Pancer, Pratt, Hunsberger, \& Alisat, 2004). As social support represents an essential component of first-year student success, a deeper understanding of how students utilize social support during their transition to higher education is paramount in creating a learning environment that provides adequate resources for incoming students. Such an understanding may be obtained by assessing social support with measures that go beyond ratings of how often students receive support (i.e., support frequency) by further exploring the quality, accessibility, and utility of received support, as well as examining support received from multiple sources with methodologies that allow for specific comparisons. As such, the present exploratory research aimed to investigate the effects of the perceived quality of social support, and the source of support, in relation to stress and other well-being outcomes among undergraduate students in Canada and the U.S. during their transition to higher education.

\section{Theoretical and Empirical Literature on First-Year Students' Social Support}

Social support is defined by Lakey and Cohen (2000) as resources from one's social environment that influence appraisals or coping related to stress. Through the lens of Lazarus and Folkman's (1984) transactional stress model, Lakey and Cohen consider social support to be an especially psychologically beneficial aspect of the social environment due to the supporting of individuals' coping resources. The psychological benefits of social support have been examined extensively in research with first-year students. Overall, study findings consistently show social support received from peers, family, faculty, or one's postsecondary institution during the first year of study to be linked to better levels of physical health (e.g., Hartung, Sproesser, \& Renner, 2015), emotional well-being (e.g., Mattanah, Brooks, Brand, Quimby, \& Ayers, 2012; Mounts, 2004), university adjustment and retention (e.g., Friedlander et al., 2007; Pancer et al., 2004), academic performance (e.g., Walton, Logel, Peach, Spencer, \& Zanna, 2015), and persistence (e.g., Chang, Sharkness, Hurtado, \& Newman, 2014; McGonagle et al., 2014). Additionally, the link between social support and psychological adjustment has been demonstrated in both quantitative research (e.g., Hausmann et al., 2007) and qualitative studies (Thompson, 2008) and with students across disciplines (e.g., psychology, engineering, nursing) and countries (e.g., Australia: Cornelius et al., 2016; Canada: Pancer et al., 2004; Netherlands: Pluut et al., 2015).

Largely, most studies conducted with first-year students have to date examined the frequency of received support, as opposed to the quality of support received. Thus, despite Gottlieb and Bergen (2010) suggesting that measures of how much support an individual receives should be supplemented by assessments of the quality of the support received, existing research with firstyear students has to date not sufficiently differentiated frequency of support received from quality of support received. As measures of support frequency only examine how often support was received (assuming that this support directly fulfills one's needs), and do not reflect the quality of support received or if the support addressed one's needs, research investigating more descriptive aspects of student support are warranted. Accordingly, received support quality thus represents an important construct to examine as a potential contributor to first-year student success alongside received support frequency, perceived availability of support, as well as personal coping strategies, stress levels, and other well-being outcomes (e.g., depression). Similarly, it is also possible that the magnitude of social support effects on first-year student adjustment could differ depending on from whom the support is received (e.g., family, friends, faculty, institution), given the potential for different sources of support to better address specific student needs (e.g., institutional support possibly better assisting with academic performance than family support).

\section{The Present Study}

The present exploratory study investigated the effects of frequency and quality of actual support received from multiple sources across critical student well-being outcomes with respect to four different sources by first-year university students in Canada and the United States. Specifically, the present study examined the extent to which the quality of social support received by students during the first month of their first semester mediated effects of frequency of received support on well-being outcomes. Informed by the theory of social support by Lakey and colleagues (e.g., Lakey \& Cohen, 2000) and the transactional model of stress and coping (Lazarus \& Folkman, 1984), the following hypotheses were examined. 


\section{Hypothesis 1}

Given empirical findings showing specific types of social support to be highly correlated yet represent distinct dimensions (see Cutrona \& Russell, 1990 for a review), measures of received support frequency and quality were anticipated to be highly correlated among first-year students. Relatedly, it was anticipated that support frequency and support quality each would explain unique variance in the well-being outcomes.

\section{Hypothesis 2}

Following from assertions across theoretical paradigms of stress and coping (Lazarus, 2000; Lazarus \& Folkman, 1984) as well as social support (Cutrona \& Russell, 1990; Lakey \& Cohen, 2000), the quality of social support received by first-year students was expected to mediate the effects of basic support frequency (i.e., how often support was received) on well-being outcomes. In other words, the anticipated benefits of more frequent received support on student well-being were expected to be largely due to this support being perceived as high-quality in nature. Although the present study additionally examined the extent to which this hypothesized mediation was potentially moderated by source of support (family, friends, faculty/staff, institution; see Figure 2), specific hypotheses as to differential magnitudes of mediation by source of support were not proposed given a notable lack of existing research with first-year students in which the benefits of different sources of support are compared.

\section{Figure 1}

Hypothesized Model of Simple Mediation Analysis (Hypothesis 2)

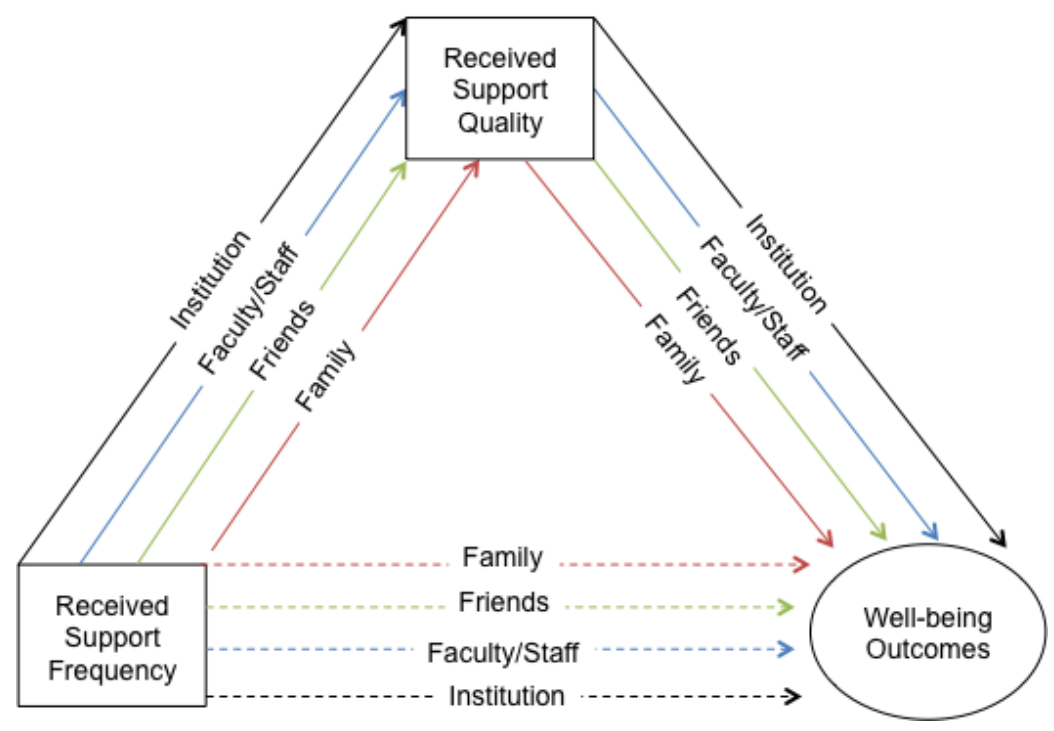

Note. Hypothesized model of simple mediation analysis (Hypothesis 2); focal predictor variable $X=$ received support frequency; mediating variable $M=$ received support quality from family, friends, faculty/staff, and institution sources. Dotted lines indicate direct effects hypothesized to be non-significant due to mediation.

\section{Methodology}

\section{Participants and Procedure}

The study sample consisted of 126 students attending higher education institutions in Canada $(89,71 \%)$ and the U.S. (37, 29\%; 36 institutions in total). Concerning gender identity, 107 students identified as female (85\%) and 18 identified as male (14\%). Students' mean age was 18.69 years $(S D=2.19), 87 \%$ reported English as their first language, and $68 \%$ self-identified as Caucasian. Students reported their current or intended disciplinary affiliations as formal sciences (e.g., computer sciences, 
mathematics, systems science; 44\%), humanities (e.g., arts, political science, psychology; 19\%), natural sciences (e.g., biology, earth sciences, physics; 13\%), and other disciplines (e.g., forensic science, nursing; 13\%). Further demographic responses indicated that $98 \%$ were enrolled as full-time students and $6 \%$ were registered as international students. Descriptive statistics for all study variables presented in Table A1 (see Supplementary Materials). Approximately one month into the academic year, first-year undergraduates were recruited for three weeks via social media (e.g., Facebook, Twitter) and on-campus advertisements to participate in an online survey in exchange for entry into a prize draw (\$50 Starbuck’s gift card).

\section{Social Support Measures}

The social support measures were designed to allow students to report on the helpfulness of the support received rather than choosing from a limited list of pre-determined actions assumed by the researcher to be supportive in nature (i.e., recipientdriven vs. researcher-driven defined support; for more on the importance of distinguishing frequency from utility of received support, see Melrose et al., 2015). Received support frequency (RSF) was measured using four items assessing how often students received social support $(0=$ never, 4 = very often $)$ from four different sources (family, friends, faculty/staff, and institution; one item for each) during the previous month. Received support quality (RSQ) was additionally assessed using four items reflecting the quality of support received by students during the previous month from family, friends, faculty/staff, and their institution (one item per source; 1 = very poor, 5 = very good).

\section{Well-Being Measures}

Received social support from each of the above-mentioned four sources was assessed alongside measures of well-being to examine if specific sources of support were more beneficial for certain well-being outcomes. Perceived stress was assessed using the short form of the Perceived Stress Scale (PSS-4; Cohen, 1986; full scale: Cohen, Kamarck, \& Mermelstein, 1983); this four-item global measure assesses stressful experiences over the previous month on a five-point Likert-type scale $(0=$ never, $4=$ very often; $\alpha=.83$ ). Burnout over the previous month was assessed using the emotional exhaustion subscale from the Maslach Burnout Inventory (MBI; Maslach \& Jackson, 1981) modified to reflect academic activities (e.g., "job" changed to "studies"; 1 = never; $6=$ every day; $\alpha=.94)$. Students' feelings of loneliness over the past month was also examined via an abbreviated version of The Revised UCLA Loneliness Scale (ULS-4; Russell, Peplau, \& Cutrona, 1980) that included four items rated on a four-point Likert-type scale $(1=$ never, $4=$ often; $\alpha=.80)$. Students' general sense of belonging over the previous month was assessed with an adapted version of the Psychological Sense of School Membership scale (PSSM; Goodenow, 1993; e.g., "school" changed to "university") that included nine items rated on a five-point Likert-type scale (1 = not at all true $; 5=$ completely true; $\alpha=.80$ ). Students' intentions to quit was measured using six questions adapted from Hackett, Lapierre, and Hausdorf (2001) assessing students' thoughts (three items; $1=$ never, 5 = constantly) and intentions (three items 1 = very unlikely, $5=$ certain ) of leaving their program, their university, and post-secondary education entirely over the previous month on a five-point Likert-type scale $(\alpha=.83)$. Finally, students' life satisfaction during their first month of studies was evaluated using an abbreviated version of the Satisfaction with Life Scale (SWLS; Pavot \& Diener, 1993) that included three items rated on a seven-point scale $(1=$ strongly disagree, $7=$ strongly agree $; \alpha=.91)$.

\section{Results}

\section{Rationale for Analyses}

Hypotheses 1 was assessed using correlational and collinearity analyses and Hypothesis 2 was examined using mediation models conducted with Hayes' PROCESS Macro in SPSS with a bootstrap sampling size of 5,000 and bias-corrected bootstrapped 95\% confidence interval (Hayes, 2013). To further explore the potential for different sources of support to moderate the proposed mediation effects (RSF $\rightarrow$ RSQ $\rightarrow$ well-being), parallel mediation models were employed for each source of support (see Figure 1). Due to preliminary MANOVA analyses showing consistent initial differences in the study variables as a function of country where the sample was taken from $\left[F(14,62)=1.33, p=.215\right.$, Wilk's $\Lambda=.769$, partial $\eta^{2}=$ . .231 ; tests of between-subjects effects significance range: $.037 \leq p \mathrm{~s} \leq .889, .000 \leq$ partial $\left.\eta^{2} \mathrm{~s} \leq .057\right]$ and gender identity $[F(14$, $62)=.887, p=.576$, Wilk's $\Lambda=.833$, partial $\eta^{2}=.167$; tests of between-subjects effects significance range: $.004 \leq p \mathrm{~s} \leq .968$, $.000 \leq$ partial $\eta^{2} \mathrm{~s} \leq .108$ ], all main analyses were conducted with institution country and gender as covariates. For ease of interpretation, unstandardized effects were reported for all models. 


\section{Hypothesis 1: Tests of Collinearity}

Collinearity statistics for the hypothesized models were examined to test independent variance for each construct. As proposed in Hypothesis 1, acceptable collinearity values were observed, with all variance inflation factors (VIF) falling below 2.50 and all tolerance tests falling above .40 (Cohen, Cohen, West, \& Aiken, 2003). As such, findings showed the RSF and RSQ measures to independently explain variance in the well-being outcomes (i.e., lack of multicollinearity) and provide empirical support for conducting the mediational analyses of Hypothesis 2 in which both variables were evaluated simultaneously.

\section{Hypothesis 2: Mediation of RSF Effects on Well-being via RSQ}

Results for models with significant indirect effects are presented in Tables A4-A9 in Appendix A (Supplementary Materials) and depicted in Figure 2. Direct effects of RSQ regressed onto RSF were significant for all models $\left(.28<R^{2}<.58, p s<.001\right)$ with results showing RSF to positively predict RSQ levels $(0.49<B<0.74, p s<.001)$.

Family support

Mediation models showed the family RSQ mediator to directly predict greater life satisfaction, $F(4,107)=5.09, p=.001, R^{2}$ $=.16(B=0.37, t=1.97, p=.051)$; however, the indirect effect of RSF via RSQ was not significant due to a lacking direct effect of RSF (see Appendix C, Table C10). No significant indirect effects of family RSF via family RSQ were found on wellbeing outcomes.

\section{Friend support}

Friend RSQ was not found to significantly mediate effects of RSF on the well-being outcomes. Greater friend RSF directly predicted lower levels of loneliness, $F(4,105)=6.13, p<.001, R^{2}=.19(B=-0.21, t=-2.71, p=.008)$; however, RSQ was not a significant predictor of loneliness (directly or indirectly from RSF).

\section{Figure 2}

Path Coefficients for Mediation Analyses on Well-being Outcomes

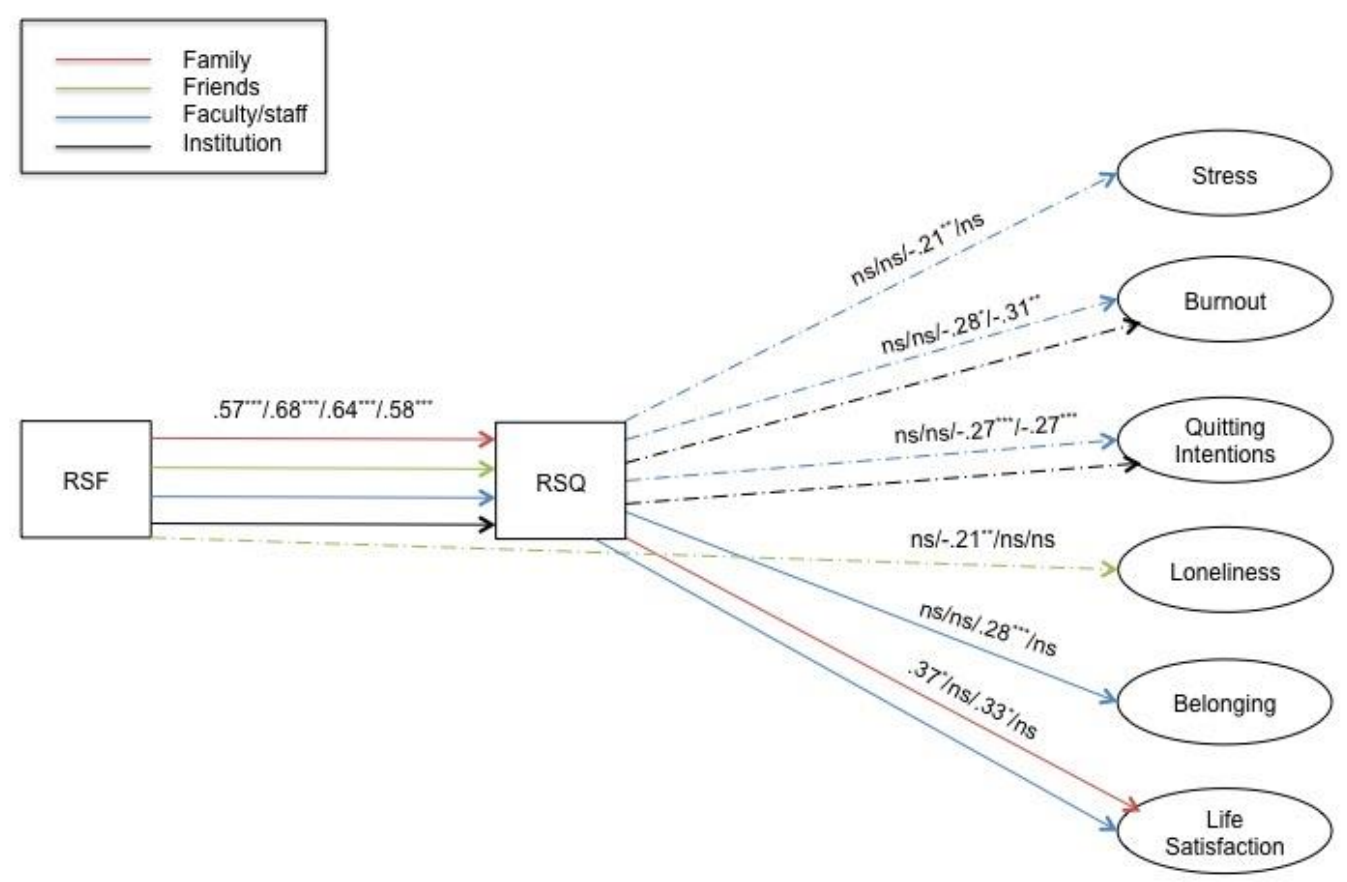


Figure 2 Note. Path coefficients for mediation analyses on well-being outcomes where focal predictor variable $X=$ received support frequency (RSF) and mediating variable $M=$ received support quality (RSQ). All coefficients are unstandardized and presented by source of support as follows: family/friends/faculty-staff/institution. Coefficients presented for paths between RSF and RSQ are for models predicting stress given similar coefficients among all outcomes. Bootstrap sample size $=5,000$. Significant direct paths were modeled, with solid lines indicating positive relationships and dotted lines indicating negative relationships. All model coefficients and standard errors are reported in Appendix A (Supplementary Materials).

${ }^{*} p<.05,{ }^{* *} p \leq .01,{ }^{* * *} p \leq .001$.

\section{Faculty/staff support}

A significant mediation effect of faculty/staff RSF effects on burnout via faculty/staff RSQ was observed, $F(4,108)=2.92, p$ $=.025, R^{2}=.10$, with a negative indirect effect of RSF via RSQ (effect of -0.19 and bootstrapped $95 \%$ CI of -.39 to -.03 ), and a direct effect of RSQ $(B=-0.28, t=-2.33, p=.022)$ when controlling for effects of RSF. Faculty/staff RSQ was also found to mediate the effect of faculty/staff RSF on belonging, $F(4,75)=12.02, p<.001, R^{2}=.39$, with a positive indirect effect of RSF via RSQ (effect of 0.14 and bootstrapped $95 \% \mathrm{CI}$ of .06 to .22 ), and a direct effect of RSQ $(B=0.28, t=3.83, p<.001)$. Additionally, significant indirect effects of faculty/staff RSF via faculty/staff RSQ, and direct effects of RSQ, were found for stress, $F(4,111)=2.77, p=.031, R^{2}=.09$, quitting intentions, $F(4,108)=4.92, p=.001, R^{2}=.15$, and life satisfaction, $F(4$, $107)=2.69, p=.035, R^{2}=.09$. Faculty/staff RSF had a negative indirect effect on stress through faculty/staff RSQ (effect of 0.13 , bootstrapped $95 \%$ CI of -.24 to -.04 ; direct negative effect of faculty/staff RSQ on stress: $B=-0.21, t=-2.58, p=.011$ ) and on quitting intentions through faculty/staff RSQ (indirect effect of -0.17 and bootstrapped $95 \%$ CI of -.30 to -.07; direct effect of RSQ: $B=-0.27, t=-3.73, p<.001)$. Conversely, faculty/staff RSF indirectly and positively predicted life satisfaction via faculty/staff RSQ (effect of 0.22 and bootstrapped 95\% CI of .03 to .45; direct effect of RSQ: $B=0.34, t=2.12, p=.036$ ).

\section{Institution support}

Institution RSF indirectly predicted lower burnout through institution $\mathrm{RSQ}, F(4,107)=2.40, p=.054, R^{2}=.08$ (effect of -0.19 and bootstrapped $95 \% \mathrm{CI}$ of -.36 to -.04 ; direct effect of RSQ: $B=-0.31, t=-2.65, p=.009)$. Institution RSF also indirectly predicted lower quitting intentions through institution RSF, $F(4,107)=4.87, p=.001, R^{2}=.15$ (effect of -.16 and bootstrapped 95\% CI of -.28 to -.06; direct effect of RSQ: $B=-0.27, t=-3.94, p<.001)$.

\section{Post-Hoc Power Analyses}

Following the main analyses, post-hoc power analyses conducted with G*Power (Faul, Erdfelder, Lang, \& Buchner, 2007; Faul, Erdfelder, Buchner, \& Lang, 2009) revealed acceptable power levels ranging from .738 to .999.

\section{Discussion}

The present empirical study aimed to explore the effects of received support on first-year undergraduate students' well-being in terms of not only how often support was received during their first month of study but also the quality of that support. Additionally, potential differences in the extent to which the effects of received support frequency (RSF) on first-year student well-being was mediated by received support quality (RSQ) were explored in relation to four specific sources of support. Using a non-conservative approach rooted in Lakey and Cohen's (2000) social support theory and Lazarus and Folkman's (1984) transactional stress model, the present exploratory study provides novel empirical evidence highlighting the importance of considering both the quality and source of support when examining how students successfully transition into higher education, particularly with respect to construct measurement and intervention programs.

\section{Study Hypotheses}

\section{Hypothesis 1: Received support frequency and quality are highly correlated but independent constructs}

Following from Hypothesis 1, relationships between RSF and RSQ were strong and positive as found in previous research examining specific components of social support (see Cutrona \& Russell, 1990 for a review). As both constructs are effectively sub-constructs comprising the broader notion of received support, high inter-correlations were expected due to 1) both indicators of received support being derived from the same action(s), and 2) one being contingent upon the other in that a 
supportive action must first occur in order for it be subsequently judged with respect to its quality. In accordance with the assumption that highly correlated predictors must explain variation in outcome variables beyond the common variance between them in multiple linear regression models (i.e., an absence of multicollinearity), VIF and tolerance tests showed RSF and RSQ to not be multicollinear and thus provide support for Hypothesis 1, and satisfy the assumption of orthogonality required to test Hypothesis 2. It is important to note, however, that as multicollinearity testing is more indicative of statistical variance inflation between predictors in a specific sample than of conceptual independence of predictors in a population, further research with other populations (e.g., in other countries) is required to establish the extent to which RSF and RSQ represent sufficiently orthogonal constructs more generally.

\section{Hypothesis 2: Received support quality mediates the effects of frequency on well-being}

The main analytical model explored the extent to which RSF effects on well-being were mediated by RSQ, and further explored whether these mediation effects differed depending on the source of support. Overall, these results provide evidence of RSQ being an important component of how the amount of support students receive facilitates their well-being during the first month of their transition to higher education, with mediation levels varying in magnitude depending on the specific source of support involved. The importance of RSQ from family members was highlighted by significant effects of RSQ on life satisfaction showing first-year students with higher family RSQ to report more life satisfaction.

In contrast, notably few findings were observed for support from friends, with the sole significant finding showing greater friend RSF to correspond with lower feelings of loneliness. However, an increased risk of Type II error due to high correlations between friend RSF and RSQ in the present study indicate that the lack of findings for friend support may be specific to this study, particularly given previous research with first-year students showing peer support to correspond with lower depression (Friedlander et al., 2007), better health (Hartung et al., 2015), and higher GPAs (Mattanah et al., 2012). Moving beyond family and friend support, results showed faculty support to be empirically linked to better levels on more well-being outcomes than support from any other source, highlighting staff involvement and faculty mentorship as a critical area of future research investigation and intervention development for first-year students. Despite students in this study reporting relatively low faculty/staff RSF (i.e., floor effects), the present findings nevertheless indicate that the quality of support first-year students received from post-secondary faculty and staff, even if support was infrequent, can have an impact on their well-being during the first few weeks of the semester. Finally, findings showing the support received by students at the institution level to be associated with lower burnout and quitting intentions further highlight the potential importance of university programming as a whole in fostering first-year student well-being (e.g., freshman orientation programs).

In summary, findings from the present exploratory study indicate that both received support frequency as well as quality are important contributors to various aspects of psychological well-being in first-year undergraduate students. As hypothesized, higher RSF via RSQ was related to optimal well-being levels. Furthermore, the magnitude of these relations was found to vary by source of support, with findings showing significant mediation for faculty/staff and institution support. Notably, RSF averages reported by students were lower for faculty/staff and institution compared to average RSF for family and friends, although average RSQ was relatively similar across sources (see Supplementary Materials, Table A1). Although these effects were relatively small in magnitude, they are consistent with effect sizes found in previous research on social support and mental health (see van der Zanden et al., 2018 for a systematic review showing relatively small effect sizes for support quality and other social-emotional well-being predictors of first-year student success) and underscore the importance of accounting for both frequency and quality of received support from specific sources in future research on the first-year experience.

In further consideration of the observed effects of RSQ on well-being outcomes, one potential factor that could impact how students perceive support quality is if the support received matched their needs. For instance, the stress-support matching hypothesis proposed by Cohen and McKay (1984) asserts that the effectiveness of specific coping strategies is largely contingent upon the nature of support received matching the specific demands of a given stressor (e.g., financial support as a match for financial stress), and that there are ideal circumstances in which an individual's needs will be satisfied. Given that received support is argued to be most beneficial when the type of support received matches the type of support needed (Cohen \& McKay, 1984; Cutrona \& Russell, 1990; Lakey \& Cohen, 2000), students' perceived quality of the support they receive, in addition to basic indicators of perceived frequency of support, should correspond with their use of coping strategies, perceived stress, and other well-being outcomes during their transition to higher education. As such, research that more explicitly examines the extent to which support received from different sources matches students' needs in specific areas (e.g., academic, financial) would be a valuable contribution to the existing literature. 


\section{Limitations and Open Questions}

Beyond the unique contributions of the present exploratory study are some limitations to be considered. First, the present sample size was relatively small thus warranting future research with larger sample sizes (e.g., across institutions, countries) to replicate the study findings and address the potential for Type II error. Additionally, larger sample sizes would afford the use of more powerful structural equation models (SEM) that allow for the estimation of effects for all sources simultaneously at the latent level (as opposed to parallel regression models for different sources). Further to interpretation and generalizability, findings for all models predicting students' sense of belonging also require replication with larger samples to address possible concerns due to lower response rates for this specific outcome. Although preliminary analyses revealed few significant differences between students who did or did not complete the belonging measure, results from the present study for relationships between received support and belonging thus warrant specific replication so as to afford greater confidence prior to generalizing to Canadian and U.S. first-year undergraduates at large.

The second limitation of this study stems from attempts to reduce response burden, particularly in relation to parallel measures of source of support (e.g., RSF, RSQ), in that single-item measures were employed. With respect to abbreviated scales and single-item measures, existing research provides empirical support for considering parsimony in survey design to reduce to participant fatigue (Fan \& Yan, 2010; Galesic \& Bosnjak, 2009), with findings underscoring the reliability and validity of various single-item, self-reported measures (e.g., college students' alcohol use, religiosity, and social life: Dollinger \& Malmquist, 2009; student-rated college teaching effectiveness: Wanous \& Hudy, 2001; job satisfaction: Dolbier, Webster, McCalister, Mallon, \& Steinhardt, 2005). However, although face-valid measures are more readily understandable by participants and have been demonstrated to have comparable psychometric validity compared to corresponding multi-item measures (Gogol et al., 2014), they are nonetheless more vulnerable to error than multi-item scales (e.g., measures of wellbeing outcomes), warranting replication with multi-item measures that provide greater specificity and internal validity.

Concerning study sampling, the over-representativeness of female (e.g., compared to male) gender identities in the present sample relative to U.S. and Canadian first-year student populations also warrants further investigation, specifically, with samples that are more representative of first-year student gender identities to ensure appropriate generalization of findings. Selection bias also presents a limitation of sampling in that students who volunteered to participate in this study may have been motivated by confounding variables. For example, highly stressed students may have been more motivated to participate as compared to students experiencing minimal stress, or conversely, highly stressed students may have been under-represented if competing demands did not allow time to participate. Lastly, as the present study is limited by its cross-sectional design, future studies are encouraged to collect longitudinal data that would afford both greater confidence in causal inference and the examination of time effects. For example, longitudinal studies could allow researchers to identify patterns of variation in received support frequency, quality, and sources of support over time as students progress through their first academic year or their entire program.

\section{Recommendations for Future Research}

Considering the aforementioned study limitations, findings from the present study present a number of opportunities for future research, particularly with respect to qualitative methods, scale development, longitudinal design, and the examination of interaction effects. Firstly, further investigation using alternate methods of assessing the type of support received by first-year students is encouraged, such as qualitative methods (e.g., interviews, diary studies) to further probe if support received matched support needed (e.g., financial, academic, psychological). Qualitative research could thus be used to inform the development of an improved self-report measure of received support that assesses not only frequency but also quality, need, matching, as well as accessibility (e.g., for students at risk of stress or lacking adequate supports). Furthermore, qualitative research examining faculty and staff experiences in providing support to first-year students is recommended to obtain a more holistic understanding of the opportunities and barriers to supporting students in transition (e.g., faculty being hesitant to support students due to a lack of counselling training).

Another recommendation pertinent to future research involves reassessing the way we quantitatively measure social support, particularly with respect to support matching. As alpha levels for combined sources of support were notably low for the singleitem measures assessed in the present study (RSF and RSQ), future research that examines combined support from multiple sources would benefit from the development of a multi-item scale that demonstrates a higher alpha level. For example, a scale recently developed by Naylor, Baik, and Arkoudis (2017) attempts to assess received support quality in terms of matching. 
Referred to as the Supported scale of the First Year Experience Scales (FYES), this measure examines support from university staff (e.g., being "given helpful advice") and thus warrants more extensive examination in future studies with first-year students, particularly given the present findings showing faculty/staff support to be critical for student well-being. Another important consideration relative to the assessment of received support in future research is that multiple sources of support should be more closely examined, for example, to explore what specific types of support at the institutional level are most effective in promoting first-year student development (as opposed to composite measures of institutional support that collapse across support types; e.g., Cornelius et al., 2016; McGonagle et al., 2014).

Longitudinal data on first-year student stress and social support could also provide useful indicators for academic support staff as to when support is most useful for students throughout the semester, such as in recent research from Australia investigating first-year student stress on a weekly basis throughout the first semester (Pitt, Oprescu, Tapia, \& Gray, 2017). With respect to studies employing a longitudinal design, future research on how stress and support intersect with other individual differences (e.g., personality traits, social goal orientation, living arrangements, socio-economic status) would provide insights as to other potential moderators of the effects of received support on student well-being. For example, research investigating individual differences in self-regulation strategies of U.S. undergraduates has shown some students to prefer embedding themselves in socially supportive environments (vanDellen, Shah, Leander, Delose, \& Bornstein, 2015), highlighting a potentially critical moderating variable.

\section{Practical Implications}

Following from recommendations for future research to examine the extent to which individual differences influence relationships between support and well-being, a deeper understanding of the mechanisms behind received support effects for both average and at-risk students could inform intervention programs at the institutional level. Continued research that emphasizes support quality could also be useful for informing institution-level support programs that involve college/university staff, such as in a recent study at McGill University in which the importance of matching students with university staff support providers based on specific student needs $(\mathrm{Ng}, 2017)$. Given results from the present study that indicate faculty/staff and institutional support to be especially important for first-year student well-being, institutional initiatives that invest in these sources of support are pertinent to ensuring that students receive high quality support that matches their needs.

As such, greater efforts to promote faculty support of first-year students is also encouraged, such as at the University of Guelph in Canada where a recent initiative to involve faculty in supporting student mental health through casual pre-arranged volunteer visits with students in campus residences has shown encouraging results (Farr, 2018). Moreover, there are increasing calls for greater professional development resources for faculty to better enable them to handle issues related student stress and mental illness (see Auberach et al. 2018 for World Health Organization findings of mental disorder prevalence in first-year undergraduates). Given emerging research drawing attention to faculty burnout due to overwork (e.g., Sabagh, Hall, \& Saroyan, 2018), it is important that faculty be supported in their efforts to facilitate students' psychological adjustment to higher education rather than be additionally burdened beyond their existing teaching, research, and service responsibilities.

\section{Conclusion}

Overall, the present research provides important findings with the potential to inform future research and program development in supporting students during the transition to higher education. As quality of support was consistently linked to well-being outcomes in the present study, future research following from the current recommendations may shed light on ways to provide quality support to undergraduates at the beginning of their first semester, particularly with respect to support from faculty, staff, and at the institutional level. The current study thus not only provides insights into the unique effects of support received from various sources, but also highlights the need for further research on the quality of social support received by first-year postsecondary students in ensuring that they are able to receive support that matches their needs during this critical transition phase. 


\section{References}

Amirkhan, J. H., \& Kofman, Y. B. (2018). Stress overload as a red flag for freshman failure and attrition. Contemporary Educational Psychology, 54, 297-308. https://doi.org/10.1016/j.cedpsych.2018.07.004

Auerbach, R. P., Mortier, P., Bruffaerts, R., Alonso, J., Benjet, C., Cuijpers, P., ... WHO WMH-ICS Collaborators. (2018). WHO World Mental Health Surveys International College Student Project: Prevalence and distribution of mental disorders. Journal of Abnormal Psychology, 127(7), 623-638. https://doi.org/10.1037/abn0000362

Chang, M. J., Sharkness, J., Hurtado, S., \& Newman, C. B. (2014). What matters in college for retaining aspiring scientists and engineers from underrepresented racial groups. Journal of Research in Science Teaching, 51(5), 555-580. https://doi.org/10.1002/tea.21146

Cohen, J., Cohen, P., West, S. G., \& Aiken, L. S. (2003). Applied multiple correlation/regression analysis for the behavioral sciences. Lawrence Erlbaum Associates, Inc.

Cohen, S. (1986). Contrasting the Hassles Scale and the Perceived Stress Scale: Who's really measuring appraised stress? American Psychologist, 716-718. https://doi.org/10.1037/0003-066X.41.6.716

Cohen, S., \& McKay, G. (1984). Social support, stress and the buffering hypothesis: A theoretical analysis. In A. Baum, S. E. Taylor, \& J. E. Singer (Eds.), Handbook of psychology and health (Vol. 4, pp. 253-267). Erlbaum.

Cornelius, V., Wood, L., \& Lai, J. (2016). Implementation and evaluation of a formal academic-peer-mentoring programme in higher education. Active Learning in Higher Education, 17(3), 193-205. https://doi.org/10.1177/1469787416654796

Coughlan, S. (2015, September 30). Rising numbers of stressed students seek help. BBC News. Retrieved from https://www.bbc.com/news/education-34354405

Cutrona, C. E., \& Russell, D. W. (1990). Type of social support and specific stress: Toward a theory of optimal matching. In B. R. Sarason, I. G. Sarason, \& G. R. Pierce (Eds.), Social support: An interactional view (pp. 319-366). Wiley.

Farr, M. (November, 2018). The compassionate professor's dilemma: What role should faculty play in supporting student mental health? University Affairs. Retrieved from https://www.universityaffairsdigital.com/universityaffairs/201812/MobilePagedArticle.action?articleId=1440036\&app=fa 1se - articleId1440036

Faul, F., Erdfelder, E., Buchner, A., \& Lang, A.-G. (2009). Statistical power analyses using G*Power 3.1: Tests for correlation and regression analyses. Behavior Research Methods, 41, 1149-1160. https://doi.org/10.3758/BRM.41.4.1149

Faul, F., Erdfelder, E., Lang, A.-G., \& Buchner, A. (2007). G*Power 3: A flexible statistical power analysis program for the social, behavioral, and biomedical sciences. Behavior Research Methods, 39, 175-191.

https://doi.org/10.3758/BF03193146

Friedlander, L. J., Reid, G. J., Shupak, N., \& Cribbie, R. (2007). Social support, self-esteem, and stress as predictors of adjustment to university among first-year undergraduates. Journal of College Student Development, 48(3), 259-274. https://doi.org/ 10.1353/csd.2007.0024

Gogol, K., Brunner, M., Goetz, T., Martin, R., Ugen, S., Keller, U., ... \& Preckel, F. (2014). "My Questionnaire is Too Long!" The assessments of motivational-affective constructs with three-item and single-item measures. Contemporary Educational Psychology, 39(3), 188-205. https://doi.org/10.1016/j.cedpsych.2014.04.002

Goodenow, C. (1993). The psychological sense of school membership among adolescents: Scale development and educational correlates. Psychology in the Schools, 30(1), 79-90. https://doi.org/10.1002/15206807(199301)30:1<79::AID-PITS2310300113>3.0.CO;2-X

Gottlieb, B. H., \& Bergen, A. E. (2010). Social support concepts and measures. Journal of Psychosomatic Research, 69(5), 511-520. https://doi.org/10.1016/j.jpsychores.2009.10.001

Haber, M. G., Cohen, J. L., Lucas, T., \& Baltes, B. B. (2007). The relationship between self-reported received and perceived social support: A meta-analytic review. American Journal of Community Psychology, 39(1-2), 133-144. https://doi.org/10.1007/s10464-007-9100-9

Hackett, R. D., Lapierre, L. M., \& Hausdorf, P. A. (2001). Understanding the links between work commitment constructs. Journal of Vocational Behavior, 58(3), 392-413. https://doi.org/10.1006/jvbe.2000.1776

Hartung, F.-M., Sproesser, G., \& Renner, B. (2015). Being and feeling liked by others: How social inclusion impacts health. Psychology \& Health, 30(9), 1103-1115. https://doi.org/10.1080/08870446.2015.1031134

Hausmann, L. R., Ward Schofield, J., \& Woods, R. L. (2007). Sense of belonging as a predictor of intentions to persist among African American and White first-year college students. Research in Higher Education, 48(7), 803-839. https://doi.org/10.1007/s11162-007-9052-9

Hayes, A. (2013). Introduction to mediation, moderation, and conditional process analysis. Guilford. 
Hefner, J., \& Eisenberg, D. (2009). Social support and mental health among college students. American Journal of Orthopsychiatry, 79(4), 491-499. https://doi.org/10.1037/a0016918

Kaul, M., \& Lakey, B. (2003). Where is the support in perceived support? The role of generic relationship satisfaction and enacted support in perceived support's relation to low distress. Journal of Social and Clinical Psychology, 22(1), 59-78. https://doi.org/10.1521/jscp.22.1.59.22761

Lakey, B., \& Cohen, S. (2000). Social support theory and measurement. In S. Cohen, L. G. Underwood, \& B. H. Gottlieb (Eds.), Social support measurement and intervention: A guide for health and social scientists (29-52). Oxford University Press.

Lazarus, R. S. (2000). Evolution of a model of stress, coping, and discrete emotions. In V. H. Rice (Ed.), Handbook of stress, coping, and health: Implications for nursing research, theory, and practice (pp. 195-222). Sage Publications.

Lazarus, R. S., \& Folkman, S. (1984). Stress, appraisal, and coping. Publishing Company, Inc.

MacDonald, G. (2017, August 16). For some students, the transition to university can be hard on mental health. The Globe and Mail. Retrieved from https://www.theglobeandmail.com/life/parenting/back-to-school/the-transition-to-universitycan-be-hard-on-mental-health/article36003286/

Maslach, C., \& Jackson, S. E. (1981). The measurement of experienced burnout. Journal of Organizational Behavior, 2(2), 99-113. Retrieved from https://onlinelibrary.wiley.com/doi/pdf/10.1002/job.4030020205

Mattanah, J. F., Brooks, L. J., Brand, B. L., Quimby, J. L., \& Ayers, J. F. (2012). A social support intervention and academic achievement in college: Does perceived loneliness mediate the relationship? Journal of College Counseling, 15(1), 22-36. https://doi.org/10.1002/j.2161-1882.2012.00003.x

McGonagle, A., Freake, H., Zinn, S., Bauerle, T., Winston, J., Lewicki, G., . . . Philion, M. (2014). Evaluation of STRONGCT: A program supporting minority and first-generation U.S. science students. Journal of STEM Education, 15(1). Retrieved from https://www.learntechlib.org/p/148290/

McKinley, C. (2013). Applying a distress-deterring approach to examine how emotional support predicts perceived stress and stress-related coping response. Southern Communication Journal, 78(5), 387-404. https://doi.org/10.1080/1041794X.2013.839737

Melrose, K. L., Brown, G. D., \& Wood, A. M. (2015). When is received social support related to perceived support and wellbeing? When it is needed. Personality and Individual Differences, 77, 97-105. https://doi.org/10.1016/j.paid.2014.12.047

Miczo, N., Miczo, L. A., \& Johnson, M. (2006). Parental support, perceived stress, and illness-related variables among firstyear college students. The Journal of Family Communication, 6(2), 97-117. https://doi.org/10.1207/s15327698jfc0602_1

Molloy, F. (2016, January 14). University burnout: It's a thing for stressed-out students. The Sydney Morning Herald. Retrieved from https://www.smh.com.au/national/university-burnout-its-a-thing-for-stressedout-students-20160113gm5ddg.html

Mounts, N. S. (2004). Contributions of parenting and campus climate to freshmen adjustment in a multiethnic sample. Journal of Adolescent Research, 19(4), 468-491. https://doi.org/10.1177/0743558403258862

Naylor, R., Baik, C., \& Arkoudis, S. (2018). Identifying attrition risk based on the first year experience. Higher Education Research \& Development, 37(2), 328-342. https://doi.org/10.1080/07294360.2017.1370438

$\mathrm{Ng}$, C. (April 8, 2017). McGill Students' Mental Health Working Group publishes open letter. The McGill Tribune. Retrieved from http://www.mcgilltribune.com/news/mcgill-students-mental-health-working-group-publishes-open-letter-516910/

Pancer, S. M., Pratt, M., Hunsberger, B., \& Alisat, S. (2004). Bridging troubled waters: Helping students make the transition from high school to university. Guidance \& Counselling, 19(4), 184-190.

Pavot, W., \& Diener, E. (1993). Review of the satisfaction with life scale. Psychological Assessment, 5(2), $164-172$.

Pitt, A., Oprescu, F., Tapia, G., \& Gray, M. (2017). An exploratory study of students' weekly stress levels and sources of stress during the semester. Active Learning in Higher Education, 19(1), 61-75. https://doi.org/10.1177/1469787417731194

Pluut, H., Curşeu, P. L., \& Ilies, R. (2015). Social and study related stressors and resources among university entrants: Effects on well-being and academic performance. Learning and Individual Differences, 37, 262-268.

https://doi.org/10.1016/j.lindif.2014.11.018

Russell, D., Peplau, L. A., \& Cutrona, C. E. (1980). The revised UCLA Loneliness Scale: Concurrent and discriminant validity evidence. Journal of Personality and Social Psychology, 39(3), 472-480. https://doi.org/10.1037/00223514.39.3.472

Sabagh, Z., Hall, N. C., \& Saroyan, A. (2018). Antecedents, correlates, and consequences of faculty burnout. Educational Research, 60(2), 131-156. https://doi.org/10.1080/00131881.2018.1461573 
Thompson, B. (2008). How college freshmen communicate student academic support: A grounded theory study. Communication Education, 57(1), 123-144. https://doi.org/10.1080/03634520701576147

van der Zanden, P. J. A. C., Denessen, E., Cillessen, A. H. N., \& Meijer, P. C. (2018). Domains and predictors of first-year student success: A systematic literature review. Educational Research Review, 23, 57-77. https://doi.org/10.1016/j.edurev.2018.01.001

van Dellen, M. R., Shah, J. Y., Leander, N. P., Delose, J. E., \& Bornstein, J. X. (2015). In good company: Managing interpersonal resources that support self-regulation. Personality and Social Psychology Bulletin, 41(6), 869-882. https://doi.org/10.1177/0146167215580778

Walton, G. M., Logel, C., Peach, J. M., Spencer, S. J., \& Zanna, M. P. (2015). Two brief interventions to mitigate a "chilly climate" transform women's experience, relationships, and achievement in engineering. Journal of Educational Psychology, 107(2), 468-485. https://doi.org/10.1037/a0037461

Welle, P. D., \& Graf, H. M. (2011). Effective lifestyle habits and coping strategies for stress tolerance among college students. American Journal of Health Education, 42(2), 96-105.

Wrench, A., Garrett, R., \& King, S. (2013). Guessing where the goal posts are: Managing health and well-being during the transition to university studies. Journal of Youth Studies, 16(6), 730-746. https://doi.org/10.1080/13676261.2012.744814

\section{Please cite this article as:}

Maymon, R., Hall, N.C., \& Harley, J.M. (2019). Supporting first-year students during the transition to higher education: The importance of quality and source of received support for student well-being. Student Success, 10(3), 64-75. https://doi.org/10.5204/ssj.v10i3.1407

This article has been peer reviewed and accepted for publication in Student Success. Please see the Editorial Policies under the 'About' section of the Journal website for further information.

Student Success: A journal exploring the experiences of students in tertiary education

(c) (1) This work is licensed under a Creative Commons Attribution 4.0 International Licence. As an open access journal, articles are free to use with proper attribution. ISSN: 2205-0795 